\title{
Reforma evaluacije i finansiranja nauke prilikom kretanja sa razine niskog učinka
}

\author{
Uvodno obraćanje
}

Štěpán Jurajda*1

\section{Izazov}

Mnoge postkomunističke zemlje u zadnje vrijeme uživaju brzu ekonomsku konvergenciju ka svojim zapadnoevropskim susjedima, ali s druge strane došlo je do iznenađujuće male konvergencije u smislu učinaka naučnog istraživanja. U 2015. godini tek oko 3\% početnih grantova Evropskog istraživačkog vijeća (ERC) poticalo je od novih članica EU. Kao što su to pokazali, na primjer, Jurajda et al. (2016), postsovjetske zemlje Evrope još uvijek znatno zaostaju u pogledu visokokvalitetnih akademskih rezultata, posebno u društvenim i medicinskim naukama, koje su ključne za kvalitetu lokalne uprave na mnogim razinama. Izdavanje publikacija u postkomunističkim zemljama također je snažno fokusirano na kvantitetu, a ne na kvalitetu. Ukratko, bibliometrijski dokazi ukazuju na to da nekoliko naučnih područja u ovim zemljama dosljedno nisu u stanju dostići naučne standarde EU-15 (na svjetskom nivou).

Postoje li naučne politike koje bi se mogle usvojiti kako bi se prevazišao ovaj jaz? Nekoliko zemalja je u zadnje vrijeme eksperimentisalo sa sistemima evaluacije i finansiranja nauke koji se oslanjaju na kvantitativne mjere kao što su broj (kvalitativno cijenjenih) publikacija ili citata. Većina iskustava iz

${ }^{*}$ CERGE-EI, a joint workplace of Charles University in Prague and the Economics Institute of the Czech Academy of Sciences. E-mail: stepan.jurajda@cerge-ei.cz

${ }^{1}$ Autor je profesor ekonomije na CERGE-EI-u, Prag, član Nacionalnog ekonomskog vijeća češke vlade, te član Vijeća za istraživanje, razvoj i inovacije češke vlade, gdje predsjedava Odborom za evaluaciju istraživačkih organizacija. Takođe je član Akademskog senata Češke akademije nauka i naučnih vijeća Češke naučne fondacije, Charles univerziteta i

Univerziteta Masaryk, te predsjednik Odbora za evaluaciju Društvenih i humanističkih nauka na Univer-zitetu Charles, predsjedavajući Odbora za evaluaciju istraživačkih instituta češkog Ministar-stva rada i socijalnih pitanja, predsjednik Vijeća za diplomiranje CERGE-a i član Izvršnog i Nadzornog odbora CERGE-EI-a, gdje je prethodno bio direktor. 
reformi bila je negativna jer kvantitativni indikatori često dovode do oportunističkog ponašanja usmjerenog na maksimiziranje indikatora, a ne kvalitete naučnih rezultata. Tipična lekcija iz ovih eksperimenata je oslanjanje na recenzije naučnih rezultata. Međutim, takvo stručno ocjenjivanje često se mora oslanjati na domaće naučnike i stoga je fundamentalno problematično u područjima nauke gdje određena zemlja daleko zaostaje za međunarodnim standardima. U širem smislu, teško pitanje je: kako se može reformirati finansiranje i evaluacija nauke kako bi se poboljšali rezultati kada čitava nacionalna područja nauke znatno zaostaju za međunarodnim standardima?

Ovo pitanje je dijelom otežano činjenicom da su niski nivoi učinka u cijelome polju obično u sprezi sa niskim nivoom finansiranja i sa unutrašnjim demokratskim procesima u akademskim krugovima, što otežava reforme i brze promjene. Ovaj rad pruža stilizirani opis nedavnih reformi finansiranja i evaluacije nauke u Češkoj Republici. Cilj mu je ilustrirati ove poteškoće i ponuditi neke prijedloge o tome kako se probiti kroz reformske blokade nudeći dvoslojne sheme finansiranja. Rasprava se djelomično temelji na opisnim dokazima iz Češke Republike i na relevantnoj naučnoj literaturi koja pokriva druge zemlje EU, ali većina ovdje ponuđenih stavova i preporuka pripada reformatoru uključenom u proces predlaganja, usvajanja i provedbe reforme finansiranja i evaluacije nauke, odnosno nisu naročito naučne prirode.

\section{Uporno nizak relativni učinak u društvenim naukama}

Sve je više dokaza da postkomunističke zemlje još nisu uspjele premostiti jaz u naučnim rezultatima u odnosu na zemlje EU-15. Slika 1 (preuzeto iz Jurajda et al., 2017) predstavlja bibliometrijsko poređenje za razdoblje 2010-2014, zasnovano na Web of Science (WoS), učinka izdavačkog rada u 226 naučnih disciplina za šest postkomunističkih država članica EU u odnosu na šest zemalja EU-15 uporedne veličine. Grafikon upoređuje svaku zemlju sa prosječnim učinkom cijelog uzorka u smislu broja članaka po glavi stanovnika na horizontalnoj osi i u smislu broja članaka po glavi stanovnika u najutjecajnijim časopisima, prema procjeni na osnovu časopisa koji pripada najboljoj četvrtini časopisi prema Article Influence Score (AIS), pokazatelju utjecaja citiranosti časopisa. Postkomunističke zemlje, s izuzetkom nekoliko naučnih disciplina uglavnom u Sloveniji, još uvijek znatno zaostaju za svojim kolegama iz EU. Iz ovih statistika također je jasno da istraživanja u postkomunističkim zemljama imaju tendenciju relativno više se fokusirati na kvantitet, a ne na kvalitet. Relativni učinak izdavačkog rada postkomunističkih zemalja 
u WoS-u posebno je slab u društvenim i medicinskim naukama, a relativno najsnažniji u prirodnim naukama i inženjerstvu.

Slika 1: Web-of-Science poređenje kvantiteta i kvaliteta objava
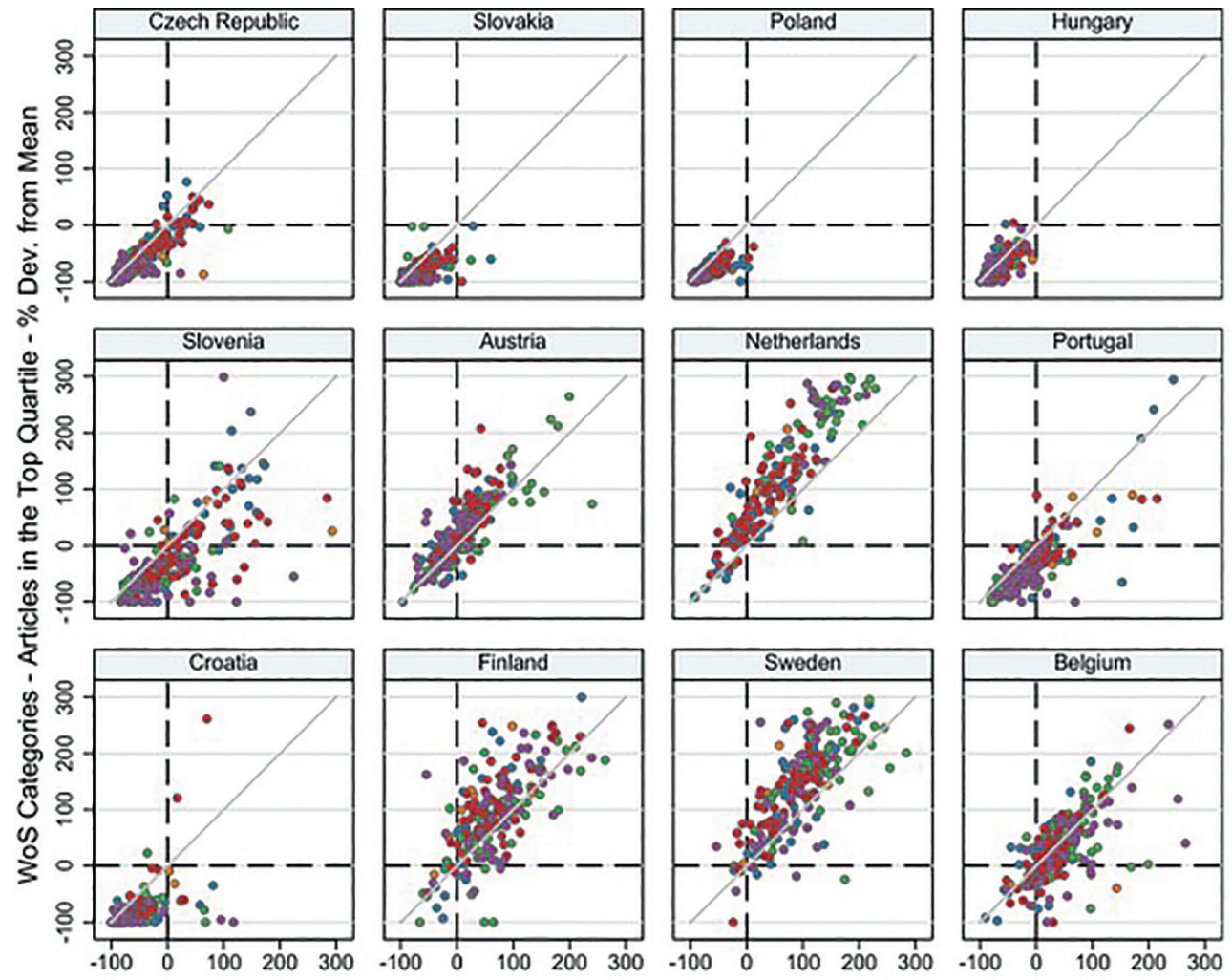

WoS Categories - All Articles - \% Deviation from Mean

- Agricultural Sciences

- Natural Sciences
- Engineering and Technology

- Social Sciences
- Medical and Health Sciences

- 45-degree line

Izvor: Jurajda et al. (2017).

\section{Finansiranje nauke u Republici Češkoj: osnovne činjenice}

Kako je organizovana administracija nauke u Češkoj? Ne postoji ministarstvo za istraživanje, a cijeli sektor za istraživanje, razvoj i inovacije (I\&R\&I) koordinira hibridno izvršno-strateško vijeće za istraživanje i razvoj (RDIC) na čelu s premijerom. Radi se o savjetodavnom tijelu vlade, koje predlaže budžete i politike, uključujući raspodjelu sredstava takozvanim ,pružateljima“ finansiranja. ${ }^{2}$

\footnotetext{
${ }^{2}$ Zemlja ima niz strateških planova i dokumenata o politici, gdje Nacionalna ekonomska strategija sadrži i Strategiju inovacija do 2030. godine, koja uključuje Nacionalnu politiku
} 
U okviru osnovnih istraživanja, ključni pružaoci institucionalnog finansiranja (blok grantova) su Ministarstvo obrazovanja (koje obezbjeđuje finansiranje univerziteta) i Akademija nauka (koja pokriva njene institute). U sektoru institucionalnog finansiranja provedene su dvije reforme finansiranja, o kojima će biti riječi u nastavku. Među ključnim pružateljima finansiranja konkurentnih programa su Češka naučna fondacija (,Agencija za grantove Češke Republike“), koja pokriva osnovne nauke, i Tehnološka agencija, koja pokriva primijenjena istraživanja i inovacije. Postoje i konkurentni programi finansiranja koji se pružaju kroz nekoliko ministarstava (industrije, zdravstva, kulture itd.). Konačno, postoji niz primjenjenih istraživačkih instituta pri određenim ministarstvima, npr. geološki institut pri Ministarstvu okoliša.

Slika 2: Javna administracija nauke u Češkoj

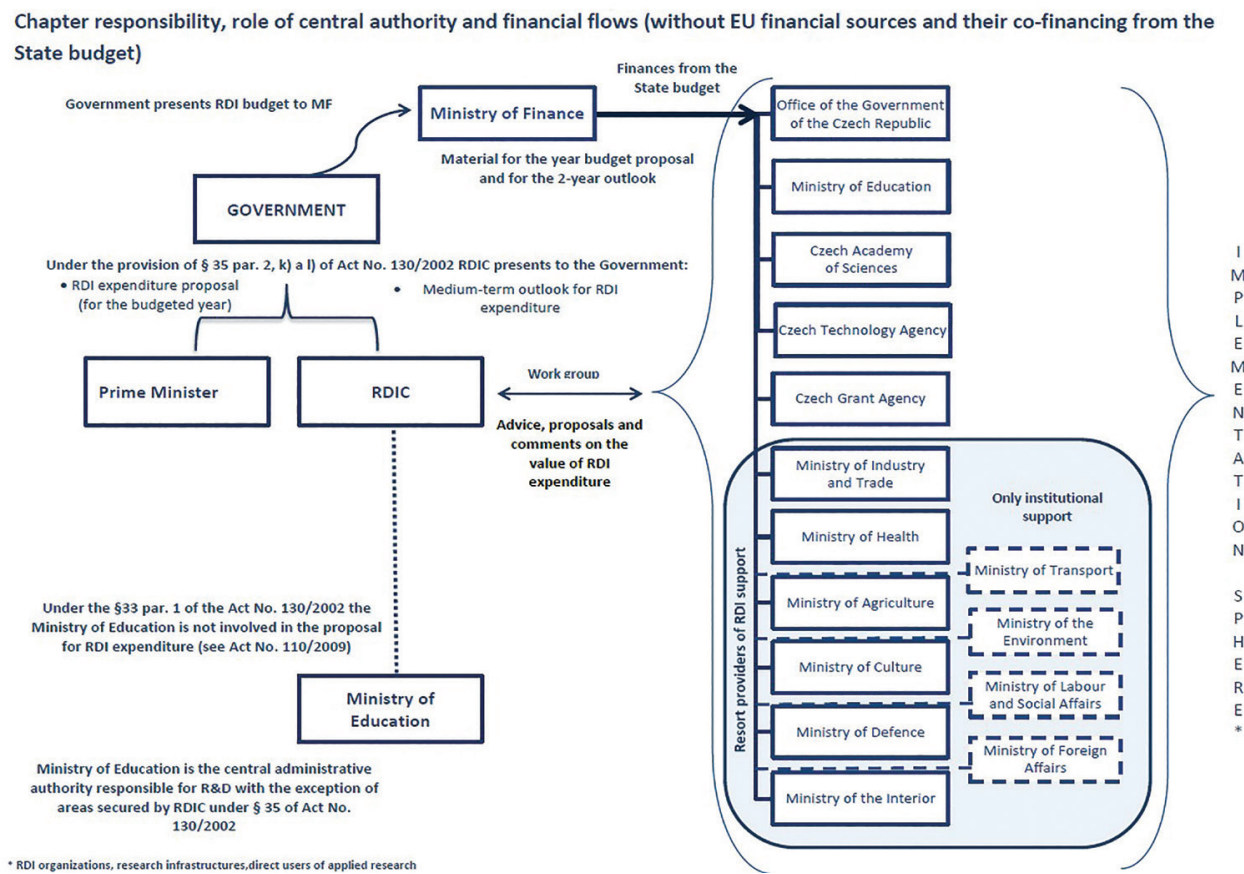

Izvor: RDIC Republike Češke

Kako se vrednuju ti kanali finansiranja? Sheme konkurentnog finansiranja zasnovane na programima kvalitativno ocjenjuju njihovi pružaoci, pri čemu se izvještaji o evaluaciji dostavljaju RDIC-u, koji odobrava produženja

istraživanja i razvoja i inovacija, koja zauzvrat uključuje Nacionalnu strategiju istraživanja i inovacija za Strategiju pametne specijalizacije (RIS3). 
programa ili ne. Institucionalno finansiranje (finansiranje osnovnog istraživanja kroz blok grantove univerziteta i istraživačkih instituta) prošlo je kroz dvije velike reforme u posljednjoj deceniji. Ove reforme su se dogodile na leđima rasta ukupnog finansiranja. Rashodi Češke Republike za istraživanje i razvoj (GERD) značajno su porasli sa 1,3\% BDP-a u 2010. na nešto manje od $2 \%$ u 2014. godini, s blagim padom nakon toga. Time je intenzitet finansiranja istraživanja Češke Republike blizu, ali i dalje ispod prosjeka EU-28. Kao što smo vidjeli na slici 1, Češka Republika znatno zaostaje za EU-15 u društvenim naukama. Prema statistikama OECD -a, Češka također ima posebno nizak udio (od 6\% u 2017) GERD-a u društvenim i humanističkim naukama. Kombinacija niskog učinka i finansiranja tipična je za društvene nauke u regionu i može odražavati komunističko naslijeđe. ${ }^{3} \mathrm{U}$ Češkoj je to također posljedica nedavne reforme finansiranja i evaluacije, koja je nanijela trajnu štetu društvenim naukama.

\section{Dvije reforme institucionalnog finansiranja u Češkoj}

Nakon generalno kritikovane sheme finansiranja zasnovane na recenzijama koja je djelovala 2000-ih, a koja se za evaluaciju oslanjala na lokalne panele niske kvalitete, češki RDIC je 2008. uveo opsežnu reformu finansiranja zasnovanu na kvantitativnim bibliometrijskim pokazateljima. Dok su druge zemlje eksperimentisale sa šemama finansiranja zasnovanim na formulama, ovo je bila prva reforma $u$ kojoj se svo institucionalno finansiranje zasnivalo na formulama, a ne na bilo kakvom odlučivanju stručnjaka/administratora.

Od 2009. češki su akademici počeli isporučivati sav svoj istraživački rezultat u vladin registar koji vodi RDIC, a koji je koristio bazu podataka o rezultatima za određivanje raspodjele oko milijardu eura finansiranja istraživanja svake godine, što je otprilike 50\% ukupnih budžetskih sredstava za istraživanje češke vlade. Formula finansiranja temeljila se na broju radova u WoS-u koje je objavila određena istraživačka jedinica, s nešto višim 'bodovima' dodijeljenim publikacijama u časopisima s većim faktorom utjecaja (IF), te na broju knjiga i drugih vrsta publikacija, pri čemu se svakoj vrsti publikacije dodjeljuje određeni broj bodova finansiranja. Ukupni budžet je tada raspodijeljen proporcionalno raspodjeli ovih bodova na određene pružaoce finansiranja koji su koristili istu transparentnu shemu za raspodjelu sredstava univerzitetima, od kojih su mnogi koristili iste formule finansiranja

\footnotetext{
${ }^{3}$ Za povezanu raspravu vidi Kovač et al. (2018).
} 
za dodjelu sredstava fakultetima, pa čak i pojedinim odjeljenjima. Ono što je najvažnije, „bodovi“ po vrsti publikacije bili su isti u svim disciplinama i područjima znanosti.

U roku od tri godine, ovaj sistem je postigao masovnu preraspodjelu sredstava sa radnih mjesta sa niskom produktivnošću na radna mjesta sa visokim produktivnošću, i iz područja nauke u kojima čak i najbolji naučnici u svijetu objavljuju samo nekoliko radova godišnje (matematika, ekonomija) u područja nauke gdje prosječni naučnik objavljuje nekoliko radova godišnje (npr. hemijsko inženjerstvo). Neki prirodno-matematički fakulteti povećali su sveukupno finansiranje u kratkom vremenskom periodu, u značajnoj mjeri na štetu društvenih i humanističkih nauka.

Brzina preraspodjele i proizvoljna priroda međudisciplinarne preraspodjele sredstava za nauku bili su toliko dramatični da je do 2013. godine uvedena izmijenjena verzija sheme finansiranja koja je fiksirala ukupne budžetske udjele u glavnim područjima znanosti (na primjer u društvenim znanostima) i dovela do masovne i grozničave utrke u okviru svakog od budžeta za pojedine oblasti, zasnovane na produkciji velike količine outputa. Iako je učinak s višim IF-om dobio više „,bodova“ nego učinak manjeg kvaliteta, ovu razliku „bodovnom“ nagrađivanju obesmislila je razlika u troškovima produkcije. $\mathrm{S}$ obzirom na to koliko je lako bilo generirati nove WoS časopise i povećati njihov IF, ${ }^{4}$ masovna produkcija outputa niske kvalitete bila je jedini način na koji su radna mjesta mogla zadržati svoj dio budžeta za određenu oblast. Ta grozničava utrka u masovnoj produkciji nije dopuštala povećanje finansiranja za radna mjesta koja su se fokusirala na povećanje kvalitete svojih rezultata. Situacija u društvenim naukama bila je posebno teška zbog dva faktora. Prvo, ukupni budžet društvenih nauka se smanjio zbog proizvoljne preraspodjele sredstava u prve tri godine reforme, što je osnažilo grozničavu utrku za finansiranje. Drugo, mnogi istraživači društvenih nauka nikada prije ove reforme nisu objavljivali u visokokvalitetnim časopisima, što je značilo da je masovna produkcija nekvalitetnih publikacija jedini način da se natječu za sredstva. ${ }^{5}$

Reforma je rezultirala značajnom preraspodjelom prema kvalitetnijim radnim mjestima u prirodnim naukama i masovnom prekomjernom produkcijom

\footnotetext{
${ }^{4}$ Tri su se prakse uglavnom koristile za napuhavanje IF-ova časopisa: Prvo, WoS Zbornik radova povezan sa lokalnim konferencijama značajno je citirao lokalno objavljivane časopise. Drugo, neki časopisi povećali su stopu samocitata. Treće, ,citatni konzorcijumi“ polu-lažnih časopisa (nekoliko ekonomskih časopisa na Baltiku, na primjer) bili su uključeni u praksu snažnog citiranja jedni drugih unutar implicitnog citatnog konzorcija.

${ }^{5}$ Neki programi društvenih nauka upućivali su svoje studente da objavljuju svoje magistarske teze u skoro pa predatorskim izdavačkim kućama, poput Lambert Academic Publishing.
} 
rezultata istraživanja niske ili nulte znanstvene vrijednosti u mnogim područjima - rezultata koji se ne bi proizveli da nije bilo moćnih transparentnih poticaja proisteklih iz finansiranja zasnovanog na formulama. U WoS kategorijama u kojima je takvo oportunističko ponašanje bilo posebno jako, uključujući nekoliko disciplina u tehničkim područjima i u društvenim naukama, Češka Republika sada proizvodi onoliko WoS članaka niske kvalitete (u najnižem, 4. kvartilu WoS AIS rangiranja) koliko bi odgovaralo jednoj petini takve proizvodnje u svim zemljama EU-15 zajedno. U posljednjih godinu dana, kao posljedica „bodovnih“ poticaja, češki ekonomisti su proizveli više ISI zbornika od svih američkih ekonomista; jasno je da isti nisu sistematski povećali naučna znanja u ovoj oblasti.

Sastav RDIC-a promijenio se oko 2014. godine, a novo Vijeće je 2017. godine uvelo još jednu veliku reformu finansiranja i evaluacije. Ova druga reforma ukinula je formularnu shemu finansiranja i zamijenila je shemom koja se u velikoj mjeri oslanja na stručne recenzije, ali disciplinira recenziranje bibliometrijskim statistikama. Novi sistem uspoređuje samo ocijenjene jedinice unutar polja, a ne između polja, i funkcionira kroz 5 modula (dimenzija) evaluacije:

- M1 - Kvalitet odabranih 10\% rezultata (stručne recenzije uz korištenje eksternih oponenata)

- M2 - Učinak istraživanja (bibliometrijska provjera kroz panele discipline)

- M3 - Društvena relevantnost (raportira se 'pružaocu')

- M4 - Održivost (raportira se 'pružaocu')

- M5 - Strategija (raportira se 'pružaocu')

Prvi modul fokusira se na stručno recenziranje publikacija koje spadaju izvan WoS-a (gdje mjerilo uticaja nije lako dostupno) i na evaluaciju WoS outputa koji se mogu izdvojiti po svom uticaju. Drugi modul fokusira se na dvije statistike za svaku ocijenjenu jedinicu unutar discipline: (a) njen profil kvalitete, gdje se veliki udio publikacija u najniže rangiranim časopisima smatra neprikladnim, i (b) njen udio u visokokvalitetnim outputima unutar discipline u odnosu na njen udio u finansiranju (kapacitet) unutar discipline. Korak normalizacije kapaciteta tek se treba u potpunosti provesti. Ponavljamo, poređenja unutar M1 i M2 vrše se samo unutar istoga polja. M1 i M2 se izvode godišnje na nacionalnom nivou (pod nadzorom RDIC-a), a zatim se ocjene sa terena agregiraju do nivoa istraživačke jedinice (univerzitet, institut) od strane 'pružatelja usluga' koji izvode vlastite korake ocjenjivanja unutar ostala tri modula, koji se rade u petogodišnjem ciklusu. 
WoS dio bibliometrijskog modula M2 oslanja se na ocjenu utjecaja članka u procesu rangiranja časopisa u 6 polja i 42 kategorije FORD disciplina (na osnovu OECD klasifikacije). WoS časopisi segmentirani su prema AIS rangiranju časopisa u 1. decil i četiri kvalitativna kvartila. Paneli pišu izvještaj za cijelu disciplinu, a zatim komentarišu profile publikacija pojedinih univerziteta.

Preraspodjela sredstava postignuta na temelju nove sheme do sada je bila minimalna, ali je reforma uspjela u tome da svi pružatelji usluga sada prihvataju da njihove odluke o finansiranju trebaju odražavati princip ,indeksnog finansiranja“, gdje bi istraživačke jedinice koje postižu veće ocjene u evaluacijama trebale ostvariti veće stope rasta njihovog institucionalnog finansiranja. Ovo je veliko poboljšanje u odnosu na prethodnu shemu, koja je svake godine (na osnovu pravila trojke) preraspoređivala sva sredstva proporcionalno „bodovima“ evaluacije zasnovanih na formuli finansiranja. To je rezultiralo velikim godišnjim povećanjima, ali i padovima finansiranja, što bi svaka shema finansiranja nauke trebala izbjegavati.

\section{Naučene lekcije: prepreke i zamke reformi}

Gore navedeni subjektivni pregled češkog iskustva u reformama dobro se uklapa u postojeću naučnu literaturu koja proučava podsticajne mjere u produkciji naučnog znanja.

\section{Štamparski stroj podsticaja kvantitativnog izdavaštva}

Postoji sve obimnija literatura o tome kako ekonomski podsticaji snažno utiču na ponašanje naučnika (Stephan, 2012). S ciljem pružanja poticaja visokokvalitetnoj nauci, reformatori često tvrde da stručno recenziranje kroz časopise i mjerenje kvaliteta časopisa (obično mjerenja broja citiranja) pružaju idealnu eksternu kvantitativnu strukturu koja se može koristiti za raspodjelu sredstava. Ova ideja dovela je do nekoliko nesretnih neželjenih posljedica u više zemalja.

Sve do gore opisane češke reforme iz 2009. godine, Australija je bila jedina zemlja koja je pokušala uvesti jednostavne bibliometrijske formule finansiranja u raspodjelu velikog dijela sredstava za istraživanje univerzitetima. Butler (2003) izvještava o efektima jednostavne formule finansiranja koja se koristi u Australiji za finansiranje univerzitetskih istraživanja, pri čemu nije učinjen nikakav pokušaj da se uzme u obzir kvalitet publikacija. Iako 
su se takve sheme finansiranja koristile od 1990. godine, njihovi budžetski udjeli bili su mali (na razini od oko 5\%). U 2001. godini, međutim, udio ukupnih sredstava usmjerenih na istraživanje i povezanih formulom dramatično se povećao. Butler (2003) pokazuje da je uvođenjem formula za finansiranje publikacija, broj publikacija u donjoj polovini časopisa rangiranih prema utjecaju citiranosti rastao dvostruko brže od broja članaka u časopisima koji su rangirani u gornjoj polovici, da se takva ,inflacija“ nekvalitetnih istraživačkih outputa dogodila u gotovo svim poljima nauke, i da se to nije dogodilo izvan univerzitetskog sektora u Australiji, tj. tamo gdje nije primijenjena ova formula finansiranja. Iako češko iskustvo do sada nije sažeto u nekoj naučnoj procjeni ove vrste, stilizirani opis koji je gore naveden podudara se s iskustvom Australije.

Italija je još jedan primjer zemlje koja je uvela bibliometrijske procjene sa vjerovatno negativnim posljedicama u smislu strateškog ponašanja naučnika. Seeber et al. (2019) pokazuju da italijanski akademici reagiraju na kvantitativne metrike citiranja koje se koriste u promocijama tako što ubrzano povećavaju broj samocitacija, pri čemu je to povećanje najizraženije za društvene nauke. U skladu s ovim nalazom, Baccini et al. (2019) ističu da se omjer u kojem citati u italijanskim publikacijama dolaze iz same Italije također povećava nakon uvođenja metrike zasnovane na citatima u akademskim evaluacije, a Bagues et al. (2019) otkrili su da je oko 5\% italijanskih istraživača, što je veliki udio, objavljivalo u časopisima koje je naučni bibliotekar Jeffrey Beall klasificirao kao ,predatorske“.

\section{Poređenje krušaka i jabuka}

Posebno nesretna karakteristika češke reforme 2008-2013 bila je dodjela istih sredstava po objavljenom članku u bilo kojoj oblasti nauke, uprkos ogromnim razlikama u praksi objavljivanja među naučnim disciplinama. Za slične neželjene posljedice plaćanja istih nivoa plaća svim istraživačima u svim disciplinama, vidi Boyle (2008).

Neprimjerene mjere vode do nesretnih podsticaja

Kada god zemlje povezuju finansiranje s faktorom utjecaja (IF) časopisa $\mathrm{u}$ kojima naučnici objavljuju, pojavljuju se novi časopisi koji omogućuju onim naučnicima koji ne mogu objavljivati u visokokvalitetnim publikacijama da pojačaju svoje 'računovodstvene' rezultate. Takvi časopisi mogu poboljšati 
svoj IF citatima u zbornicima lokalno organiziranih konferencija, i to često čine. Jedan od načina da se izbjegnu ovi poticaji ,štamparskog stroja“ je oslanjanje na ocjenu utjecaja članaka (Article Influence Score - AIS). AIS je također prosječna mjera uticaja po članku zasnovana na citatima u Web of Science (WoS), ali ima nekoliko važnih prednosti u odnosu na IF. Veću težinu stavlja na citate iz prestižnijih časopisa, a zanemaruje citiranje članaka iz istog časopisa, otežavajući manipulaciju. Takođe je važno izbjeći ugrožavanje humanističkih nauka na osnovu činjenice da takav eksterni indikator za kvalitet nije dostupan za knjige i časopise koji nisu dio WoS-a.

Dodatni problem pri restrukturiranju raspodjele sredstava je to što se žele izbjeći nepredvidive brze promjene u finansiranju. Osnovna karakteristika produkcije naučnog znanja je da izgradnja visokokvalitetnih timova (odjeljenja, škola) zahtijeva niz godina, ali se oni mogu brzo poremetiti privremenim nedostatkom odgovarajućih sredstava. To nalaže da sheme finansiranja ne uvode velike fluktuacije u finansiranju iz godine u godinu. Slično, iako konkurentno (tj. grantovsko) finansiranje daje poticaj za rast kvalitete, kada je udio konkurentnog finansiranja u odnosu na institucionalno (blok-grant) finansiranje previsok, i ovo stvara previše neizvjesnosti koja ograničava sposobnost ambicioznih radnih mjesta da održe uzlaznu putanju kvaliteta. U tipičnom okruženju, ovo nije obavezujuće pitanje jer se status quo obično održava internim akademskim demokratskim procesima, ali češka reforma 2009-2010 pokazuje da reformski napori mogu otići predaleko. To znači da bi preraspodjela sredstava prema radnim mjestima višeg kvaliteta ili pojedincima idealno trebala doći iz ukupnog povećanja dodatnih sredstava, a ne na štetu njihovih konkurenata u sistemu.

\section{Zaključci i preporuke}

Glavne lekcije iz češke reforme mogu se sažeti na sljedeći način: Rast ukupnog finansiranja otvara vrata reformama, ali bez evaluacija prema međunarodnim standardima, napredak je spor ili nikakav. Sve prakse evaluacije moraju se izvoditi strogo unutar disciplina. Formulativni ,transparentni“ poticaji mogu imati negativne efekte, pa je oslanjanje na stručne recenzije od kritičnog značaja, ali to otvara još jedno ključno pitanje ko određuje sastav panela za ocjenjivanje. Međunarodni savjetodavni odbori mogu biti od pomoći. ${ }^{6}$

\footnotetext{
${ }^{6}$ U kontekstu Češke Republike, Češka naučna fondacija podugovara neke od svojih evaluacija sa ESF-Science Connect-om. RDIC ima Međunarodni savjetodavni odbor, koji uključuje vrhunske češke naučnike koji rade u inostranstvu. Svi češki univerziteti i neki instituti Češke
} 
$\mathrm{Na}$ osnovu ovih lekcija mogu se formulisati dvije preporuke: (i) Pokušati da se što više posveti eksternim evaluacijskim mjerilima koja nisu zasnovana na formulama, kao što je broj dodijeljenih ERC grantova po oblastima. Ako lokalni napori srednjeročno ne naprave razliku na osnovu takvih eksternih mjerila, na kraju će se ocijeniti da nisu uspješni. (ii) Kada god postoji mogućnost za rast javnog finansiranja, podijeliti finansiranje na glavni postojani dio, koji je dostupan postojećoj naučnoj zajednici sa visokim nivoom predvidljivosti i kontinuiteta, i strukturno odvojeni nivo finansiranja koji je fokusiran samo na visokokvalitetne učinke. Ovaj drugi nivo u idealnim prilikama se u raspodjeli sredstava može osloniti na evaluacione i savjetodavne odbore sastavljene od naučnika sa vodećih svjetskih istraživačkih institucija, uključujući i one iz dijaspore.

Vrlo ambiciozan projekt u okviru ove druge razine bio bi uspostavljanje velikog centra izvrsnosti poput austrijskog IST-a (vidi https:/ist.ac.at/en/ home/). ${ }^{7}$ Možda je realnije uspostavljanje programa velikih grantova usmjerenih na osobu (slično kao i kod ERC natječaja, ali na nižem nivou očekivanja i finansiranja, primjeri uključuju EXPRO grantove Češke naučne fondacije, grantove Lumina Quaeruntur Češke akademije nauka ili Dioscuri centre MPG mreže), kao i sheme finansiranja na radnom mjestu. Jedan primjer, gdje je podrška međunarodno konkurentnim poduhvatima poželjna na nivou radnog mjesta (za razliku od nivoa osobe) su doktorske studije. Postoje primjeri dobre prakse koje treba slijediti pri kreiranju konkursa za najbolji doktorski program u zemlji u svim oblastima, i u velikodušnoj podršci tom programu (i njegovom fakultetu) (npr. LC centri češkog Ministarstva obrazovanja 2000-ih ili velika njemačka Exzellenzinitiative). Ako se takvi napori pokažu kao preambiciozni, svaka nacionalna evaluacija koja pruža veću stopu rasta finansiranja najbolje ocijenjenim institucijama na osnovu upoređivanja striktno unutar istog polja također će vjerovatno postupno napraviti razliku.

akademije nauka sada imaju Međunarodni savjetodavni odbor. Nekoliko nobelovaca je trenutno uključeno u neke od ovih odbora.

${ }^{7}$ Ovo ne mora zahtijevati nove građevine budući da može odgovarati distribuiranom centru sa svojim upravnim odborom. Općenito, iako su ulaganja u zgrade i laboratorije (opremu) često vrlo važna, kritični aspekt znanstvenog napretka je ljudski kapital i sposobnost privlačenja i zadržavanja perspektivnih istraživača koji tada mogu pomoći u prikupljanju sredstava za njihovu opremu. 


\section{Reference}

Butler, L. (2003) "Modifying publication practices in response to funding formulas," Research Evaluation, 12 (1), 39-46.

Baccini, A., De Nicolao, G., and E. Petrovich (2019) "Citation gaming induced by bibliometric evaluation: A country-level comparative analysis," PLOS ONE, 14(9).

Bagues, M., Sylos-Labini, M., and N. Zinovyeva (2019) "A Walk on the Wild Side: 'Predatory' Journals and Information Asymmetries in Scientific Evaluations," Research Policy, 48(2): 462-477.

Boyle, G. (2008) "Pay Peanuts and Get Monkeys? Evidence from Academia," The B.E. Journal of Economic Analysis \& Policy: 8(1), Article 21.

Jurajda, Š., Kozubek, S., Münich, D., and S. Škoda (2017) "Scientific publication performance in postcommunist countries: still lagging far behind." Scientometrics 112, 315328.

Kovač, D., Scrbec, N., and B. Podobnik (2018) "Does it Pay Off to Research Economics-A Tale of Citation, Knowledge and Economic growth in Transition Countries," Physica A: Statistical Mechanics and its Applications, 505(1): 293-305.

Seeber, M., Cattaneo, M., Meoli, M., and P. Malighetti (2019) "Self-citations as Strategic Response to the Use of Metrics for Career Decisions," Research Policy, 48(2): 478-491.

Stephan, P. (2012) How Economics Shapes Science, Harvard University Press. 